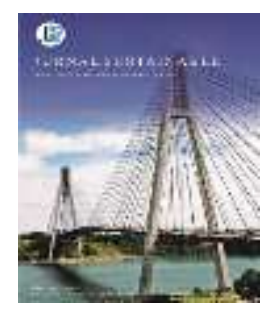

\title{
Perancangan Media Pembelajaran Interaktif Berbasis Android pada Mata Pelajaran Ilmu Pengetahuan Sosial untuk Anak Sekolah Dasar
}

\author{
Ellbert Hutabri ${ }^{1, *}$, Anggia Dasa Putri ${ }^{2}$ \\ ${ }^{1,2}$ Jurusan Teknik Informatika, Fakultas Teknik dan Komputer, Universitas Putera Batam \\ ${ }^{1,2}$ Jl. R. Soeprapto - Batam \\ *Corresponding Author: ellbert.hutabri@gmail.com, anggiaputri4@gmail.com
}

\begin{abstract}
Technology is increasingly developing in all aspects of life, even in the teaching and learning process. Children at Elementary School level are more interested in learning with interactive learning media that are more interesting than conventional learning from textbooks. Learning to use textbooks makes it difficult for elementary school age children to concentrate because of the large amount of material, books that are less interesting and lack of interaction so that when learning students must be guided especially for Social Sciences subjects. With the Android-based interactive learning media application, students can learn while playing. The media is designed to contain material in the form of images, audio and video so as to attract the attention and concentration of students in the learning process independently. This media design uses the RAD (Rapid Application Development) and Unified Modeling Language (UML) methods as a tool for modeling media, android studio for its design. Based on the results of trials conducted on elementary school students feel more interested and easier to remember material with interactive media than learning to use textbooks.
\end{abstract}

Keywords - Media, Interactive Media, Social Sciences, Elementary Schools, Android

Intisari-Teknologi semakin berkembang dalam semua aspek kehidupan, bahkan dalam proses belajar mengajar. Anak-anak pada tingkat Sekolah Dasar lebih tertarik belajar dengan media pembelajaran interaktif yang lebih menarik dibandingkan pembelajaran konvensional dari buku pelajaran. Belajar menggunakan buku paket membat anak usia Sekolah Dasar sulit berkonsentrasi karena banyaknya materi, buku yang kurang menarik dan kurangnya interaksi sehingga ketika belajar siswa harus dilakukan pembimbingan terutama untuk mata pelajaran Ilmu Pengetahuan Sosial. Dengan adanya aplikasi media pembelajaran interaktif berbasis android, siswa dapat belajar sambil bermain. Media yang dirancang memuat materi dalam bentuk gambar, audio dan video sehingga dapat menarik perhatian serta konsetrasi siswa dalam proses belajar secara mandiri. Pernacangan media ini menggunakan metode RAD (Rapid Application Development) dan Unified Modeling Language (UML) sebagai alat bantu memodelkan media, android studio untuk perancangannya. Berdasarkan hasil uji coba yang dilakukan pada siswa Sekolah Dasar merasa lebih tertarik dan lebih mudah mengingat materi dengan media interaktif dibandingkan belajar menggunakan buku paket.

Kata kunci-Media, Media Interaktif, Ilmu Pengetahuan Sosial, Sekolah Dasar, Android.

\section{Pendahuluan}

Perkembangan teknologi yang merambah keseluruh lini kehidupan manusia merubah ke gaya hidup manusia termasuk perilaku dan dan gaya belajar. Perubahan gaya belajar ini sangat dirasakan jika dahulu guru dalam proses belajar 
mengajar hanya menggunakan papan tulis sebagai media, saat ini guru sudah menggunakan komputer jinjing dan proyektor dalam menyampaikan materinya. Mata pelajaran Ilmu Pengetahuan Sosial (IPS) berbeda dengan ilmu pengetahuan mono disiplin. IPS [1] adalah ilmu yang menggabungkan antar disiplin ilmu sosial seperti geografi, ekonomi, sosiologi atau antropologi. Materi pada mata pelajaran ini bersifat teori dan cukup banyak, sehingga guru harus menyampaikan materi dengan cara yang menarik.

Berdasarkan observasi yang dilakukan, guru menyampaikan materi yang berasal dari buku paket dan menjelaskannya di depan kelas dengan bantuan media papan tulis, model pembelajaran ini dirasa siswa kurang menarik, siswa cepat merasa bosan, sulit berkonsentrasi, sebagian besar siswa masih sulit memahami materi, sehingga berdampak kepada nilai mata pelajaran.

Suatu media dikatakan baik [2] apabila dapat meningkatkan kreatifitas, minat dan motivasi belajar siswa. Media [3] merupakan alat yang digunakan untuk memberikan ransangan bagi peserta didik agar terjadi proses belajar.

Berdasarkan masalah di atas perlu dibuat suatu media pembelajaran yang interaktif agar dapat proses belajar mengajar menjadi lebih menarik dan siswa dapat belajar secara mandiri.

Perancangan media ini menggunakan metode RAD (Rapid Application Development) dengan pendekaatan berorientasi objek dan memanfaatkan UML sebagai tools untuk pengembangan media berbasis android.

\section{LANDASAN TEORI}

\section{A. Media Interaktif}

Media pembelajaran [4] adalah perantara yang bertujuan untuk menyampaikan pesan dalam proses pembelajaran. Sedangkan media interaktif [5] adalah proses pemberdayaan siswa untuk mengendalikan lingkungan belajar. Lingkungan belajar yang dimaksud adalah belajar dengan memanfaatkan teknologi, dalam hal ini smartphone berbasis android.

\section{B. Android}

Android [6] merupakan sistem operasi yang dikembangkan untuk perangkat mobile. Sistem operasi ini dirancang untuk perangkat mobile berlayar sentuh seperti smartphone dan tablet berbasis Linux. Android dibeli oleh google pada tahun 2005, awalnya android dikembangan oleh Android, Inc., dengan dukungan keuangan dari Google.

Android dikembangkan oleh Open Handset Alliance (OHA) yang merupakan gabungan dari berbagai perusahaan. Didirikannya Open Handset Alliance (OHA) bertujuan untuk mengembangkan teknologi mobile device. Open Handset Alliance (OHA) terdiri dari 34 perusahaan yang diketuai oleh Google. Android bersifat open source karena sumber code atau source code dari sistem operasi android dapat dilihat, dirubah, dan didownload secara gratis atau bebas. Android digunakan sebagai sistem operasi untuk berbagai perangkat mobile seperti smartphone dan tablet.

\section{UML (Unified Modeling Languange)}

Unified Modeling Language (UML) [7] merupakan bahasa pemodelan perangkat lunak yang digunakan untuk perancangan sistem yang berorientasi objek. UML dapat menggambarkan perangkat lunak yang dirancang secara visual, mendokumentasi, serta menspesifikasikannya agar mudah dipahami oleh programer dan user.

Beberapa diagram pada UML adalah sebagai berikut :

\section{1) Use Case Diagram}

Use case diagram atau diagram use case adalah diagram untuk memodelkan perilaku suatu sistem yang akan dirancang dengan menggambarkan interaksi antara satu atau lebih aktor yang akan menggunakan sistem.

Tabel 1. Notasi use case diagram

\begin{tabular}{ll}
\hline \multicolumn{1}{c}{ Simbol } & \multicolumn{1}{c}{ Deskripsi } \\
\hline nama & $\begin{array}{l}\text { Merupakan fungsi atau } \\
\text { kegunaan sistem untuk } \\
\text { unit atau sistem } \\
\text { pertukaran pesan antara } \\
\text { unit dan aktor. }\end{array}$ \\
\hline
\end{tabular}




\begin{tabular}{|c|c|}
\hline $\begin{array}{l}\text { } \\
\text { Actor (aktor) } \\
\text { nama aktor }\end{array}$ & $\begin{array}{l}\text { Merupakan aktor atau } \\
\text { orang, sistem atau proses } \\
\text { yang berperan dan } \\
\text { memiliki } \\
\text { dengan sistem informasi } \\
\text { yang dibuat. }\end{array}$ \\
\hline $\begin{array}{l}\text { Association } \\
\text { (asosiasi) }\end{array}$ & $\begin{array}{l}\text { Merupakan interaksi aktor } \\
\text { dengan use case atau } \\
\text { komunikasi antara aktor } \\
\text { dan use case. }\end{array}$ \\
\hline Extend (Ekstensi) & $\begin{array}{l}\text { Merupakan relasi } \\
\text { tambahan use case dengan } \\
\text { use case lain. Tanpa use } \\
\text { case yang yang } \\
\text { ditambahkan Use case } \\
\text { dapat berdiri. Arah dari } \\
\text { panah ke arah use case } \\
\text { yang ditambahkan. }\end{array}$ \\
\hline $\begin{array}{l}\text { Generalization } \\
\text { (Generalisasi) }\end{array}$ & $\begin{array}{l}\text { Merupakan hubungan } \\
\text { umum }- \text { khusus } \\
\text { (generalisasi dan } \\
\text { spesialisasi) untuk dua use } \\
\text { case. Satu use case } \\
\text { memiliki fungsi yang } \\
\text { lebih general (umum), dari } \\
\text { use case yang lainnya. } \\
\text { Arah panah menunjukkan } \\
\text { arah ke use case yang } \\
\text { umum. }\end{array}$ \\
\hline 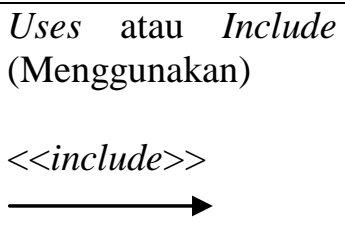 & $\begin{array}{l}\text { Merupakan relasi dua use } \\
\text { case, use case yang } \\
\text { ditambahkan dengan use } \\
\text { case tambahan. Use case }\end{array}$ \\
\hline$<<$ uses $>>$ & $\begin{array}{l}\text { memerlukan use case } \\
\text { tambahan untuk } \\
\text { menjalankan kegunaan } \\
\text { atau fungsi sebagai syarat } \\
\text { menjalankan use case }\end{array}$ \\
\hline
\end{tabular}

2) Activity Diagram

Diagram aktivitas (activity diagram) mendeskripsikan aliran kerja (workflow) atau aktivitas sistem atau proses bisnis atau menu yang terdapat di dalam sistem atau perangkat lunak.

Tabel 2. Notasi activity diagram

\begin{tabular}{|c|c|}
\hline Simbol & Deskripsi \\
\hline Status awal/ Akhir & $\begin{array}{lr}\text { Merupakan } & \text { status } \\
\text { awal atau akhir } & \text { akan } \\
\text { keadaan dari } & \text { sistem, } \\
\text { setiap } & \text { diagram } \\
\text { aktivitas } & \text { memiliki } \\
\text { satu status awal. }\end{array}$ \\
\hline Aktivitas & $\begin{array}{lr}\text { Merupakan } & \text { kegiatan } \\
\text { yang } & \text { dilakukan } \\
\text { sistem, r } & \text { sering } \\
\text { dimulai } & \text { dengan kata } \\
\text { kerja. } & \end{array}$ \\
\hline Decision (Percabangan) & $\begin{array}{l}\text { Merupakan hubungan } \\
\text { percabangan untuk } \\
\text { keputusan aktivitas } \\
\text { yang memiliki lebih } \\
\text { dari satu pilihan. }\end{array}$ \\
\hline Join (Penggabungan) & $\begin{array}{l}\text { Merupakan hubungan } \\
\text { penggabungan jika } \\
\text { satu atau lebih } \\
\text { aktivitas menjadi } \\
\text { satu. }\end{array}$ \\
\hline Swimlane & $\begin{array}{l}\text { Merupakan yang } \\
\text { memisahkan } \\
\text { organisasi bisnis. } \\
\text { Memiliki tanggung } \\
\text { jawab untuk aktivitas } \\
\text { yang terjadi. }\end{array}$ \\
\hline
\end{tabular}

\section{3) Sequence Diagram}

Diagram Sekuen (Sequence Diagram) mendeskripsikan perilaku objek pada use case dengan menjelaskan alur waktu hidup dari objek dan pesan atau message yang diterima dan dikirim antar objek.

Tabel 3. Notasi sequence diagram

\begin{tabular}{cl}
\hline Simbol & \multicolumn{1}{c}{ Deskripsi } \\
\hline $\begin{array}{c}\text { Aktor } \\
\text { nama aktor }\end{array}$ & $\begin{array}{l}\text { Merupakan orang } \\
\text { atau sistem lain atau } \\
\text { proses diluar sistem }\end{array}$ \\
nama aktor & $\begin{array}{l}\text { yang dibuat, yang } \\
\text { berhubungan dengan }\end{array}$ \\
sistem yang dibuat. \\
Aanpa waktu aktif & Aktor belum tentu \\
& orang, walaupun \\
memiliki simbol \\
bergambar orang.
\end{tabular}


E. Hutabri dan A. Dasa Putri, Perancangan Media Pembelajaran Interaktif Berbasis Android pada Mata Pelajaran Ilmu Pengetahuan Sosial untuk Anak Sekolah Dasar

\begin{tabular}{|c|c|}
\hline Lifeline (Garis hidup) & $\begin{array}{ll}\text { Merupakan garis } \\
\text { hidup objek yang } \\
\text { menerangkan } \\
\text { kehidupan objek. }\end{array}$ \\
\hline Objek & \multirow{2}{*}{$\begin{array}{l}\text { Merupakan objek } \\
\text { yang melakukan } \\
\text { interaksi pesan. }\end{array}$} \\
\hline Nama objek:nama & \\
\hline Waktu aktif & $\begin{array}{l}\text { Merupakan simbol } \\
\text { yang menyatakan } \\
\text { bahwa objek dalam } \\
\text { keadaan berinteraksi } \\
\text { dan keadaan aktif, } \\
\text { dan semua yang } \\
\text { berhubungan dengan } \\
\text { waktu } \\
\text { merupakan tahapan } \\
\text { yang di lakukan } \\
\text { selama dalam } \\
\text { keadaan aktif. }\end{array}$ \\
\hline $\begin{array}{c}\text { Pesan tipe create } \\
\qquad<<\text { create }>>\end{array}$ & $\begin{array}{l}\text { Merupakan } \\
\text { pernyataan satu objek } \\
\text { membuat objek lain. }\end{array}$ \\
\hline $\begin{array}{l}\text { Pesan tipe call } \\
\text { 1: nama_metode() }\end{array}$ & $\begin{array}{l}\text { Merupakan } \\
\text { pernyataan satu objek } \\
\text { memanggil metode } \\
\text { atau operasi pada } \\
\text { objek lain atau diri } \\
\text { sendiri. }\end{array}$ \\
\hline $\begin{array}{l}\text { Pesan tipe send } \\
\text { 1: masukan }\end{array}$ & $\begin{array}{l}\text { Merupakan } \\
\text { pernyataan bahwa } \\
\text { objek mengirimkan } \\
\text { informasi atau } \\
\text { masukan atau data ke } \\
\text { objek lain. }\end{array}$ \\
\hline 1: keluaran & $\begin{array}{l}\text { Merupakan } \\
\text { pernyataan bahwa } \\
\text { objek menjalankan } \\
\text { metode atau operasi } \\
\text { yang memberi hasil } \\
\text { suatu pengembalian } \\
\text { atau keluaran ke } \\
\text { objek tertentu. }\end{array}$ \\
\hline Pesan tipe destroy & $\begin{array}{l}\text { Merupakan } \\
\text { pernyataan bahwa } \\
\text { satu } \\
\text { mengakhiri } \\
\text { dari objek lain, jika } \\
\text { ada create lebih baik } \\
\text { ada destroy. }\end{array}$ \\
\hline
\end{tabular}

\section{4) Class diagram}

Class Diagram atau Diagram kelas digunakan untuk membuat sistem dengan mendeskripsikan struktur sistem dari sisi pendefinisian kelas yang dibuat. Kelas memiliki variabel-variabel yang dimiliki oleh kelas (atribut) dan fungsi-fungsi yang dipunyai oleh kelas (metode atau operasi).

Tabel 4. Notasi Class Diagram

\begin{tabular}{|c|c|}
\hline Simbol & Deskripsi \\
\hline Class (Kelas) & \multirow{4}{*}{$\begin{array}{l}\text { Merupakan kelas yang ada } \\
\text { pada struktur sistem. } \\
\text { Memiliki atribut dan } \\
\text { operasi dalam kelas. }\end{array}$} \\
\hline Nama_kelas & \\
\hline+ atribut & \\
\hline +operasi() & \\
\hline
\end{tabular}

\begin{tabular}{ll}
\hline $\begin{array}{l}\text { Interface } \\
\text { (antarmuka) }\end{array}$ & $\begin{array}{l}\text { Merupakan kemiripan } \\
\text { dengan kelas tetapi } \\
\text { memiliki metode yang di } \\
\text { deklarasikan tanpa isi dan } \\
\text { tanpa atribut kelas. }\end{array}$ \\
nama_interface &
\end{tabular}

\begin{tabular}{llr}
\hline $\begin{array}{l}\text { Association } \\
\text { Asosiasi) }\end{array}$ & $\begin{array}{l}\text { Merupakan } \\
\text { antarkelas } \\
\text { biasanya delasi } \\
\text { dengan miltiplicity. }\end{array}$ \\
\hline $\begin{array}{l}\text { Directed association } \\
\text { (Asosiasi berarah) }\end{array}$ & $\begin{array}{l}\text { Merupakan relasi antara } \\
\text { kelas bermakna satu kelas } \\
\text { digunakan oleh kelas yang } \\
\text { lain, biasanya dilengkapi } \\
\text { dengan multiplicity. }\end{array}$ \\
\hline Generalisasi & $\begin{array}{l}\text { Merupakan relasi antara } \\
\text { kelas } \\
\text { generalisasi-spesialisasi } \\
\text { (umum ke khusus). }\end{array}$ \\
\hline $\begin{array}{l}\text { Dependency } \\
\text { (Kebergantungan) }\end{array}$ & $\begin{array}{l}\text { Merupakan relasi } \\
\text { kebergantungan } \\
\text { (dependency) antara kelas }\end{array}$ \\
\hline $\begin{array}{l}\text { Aggregation } \\
\text { (Agregasi) }\end{array}$ & $\begin{array}{l}\text { Merupakan relasi antara } \\
\text { kelas bermakna semua- } \\
\text { bagian (whole-part) }\end{array}$ \\
&
\end{tabular}

\section{Metode Penelitian}

Pengembangan media menggunakan metode RAD (Rapid Application Development) [8] merupakan metode pengebangan sistem dengan waktu yang reltif singkat. Tahap pengembangan RAD adalah :

\section{A. Merencanakan kebutuhan}


Pada tahap ini analis dan end user melakukan pertemuan untuk menentukan tujuan dari perancangan yang akan dilakukan. Dalam penelitian ini adalah melakukan wawancara dengan guru dan siswa untuk menggali informasi mengenai media yang dibutuhkan dalam belajar IPS.

B. Analisis

Analisis dilakukan terhadap standar kompetensi, kompetensi dasar, siswa. Analsis ini bertujuan untuk mendapatkan pemahaman secara keseluruhan terhadap aplikasi yang dirancang agar sesuai dengan karakteristik serta kemampuan siswa.

\section{Proses Desain}

Pada tahap proses desain melakukan desain terhadap aplikasi dan merncocokan dengan saran dari user, apabila ada kesalahan maka akan dilakukan perbaikan terhadap aplikasi desain yang dibuat masih pada tahap paper based menggunakan UML.

D. Implementasi

Tahap ini adalah merubah desain paper based menjadi komputer based. Dalam hal ini adalah merubah rancangan awal yang telah didiskusikan dengan user kedalam bentuk aplikasi berbasis android dengan menggunakan android studio.

\section{E. Pengujian}

Aplikasi yang dirancang dilakukan pengujian terhadap siswa dan guru dengan harapan aplikasi ini dapat dimemenuhi kebutuhan siswa agar proses belajar mengajar menjadi lebih menarik.

\section{F. Perawatan}

Merupakan tahap dimana aplikasi yang dirancang telah digunakan dan akan dilakukan perbaikan-perbaikan kecil jika ditemukan kesalahan.

\section{Analisis dan Pembahasan}

Analsisi dilakukan terhadap proses pembeajaraan. Dengan mengamati proses belajar megajar dan membandingkan dengan nilai siswa. Pada tahap ini dianalisis juga materi, standar kompetensi, kompetensi dasar, dan siswa. Hasil analisis diimplementasikaan dalam desain aplikasi berbantuan UML.

\section{A. Use case diagram}

Menggambarkan hubungan antara user dengan aplikasi yang dirancang. Berikut use case perancangan aplikasi media pembelajaran IPS

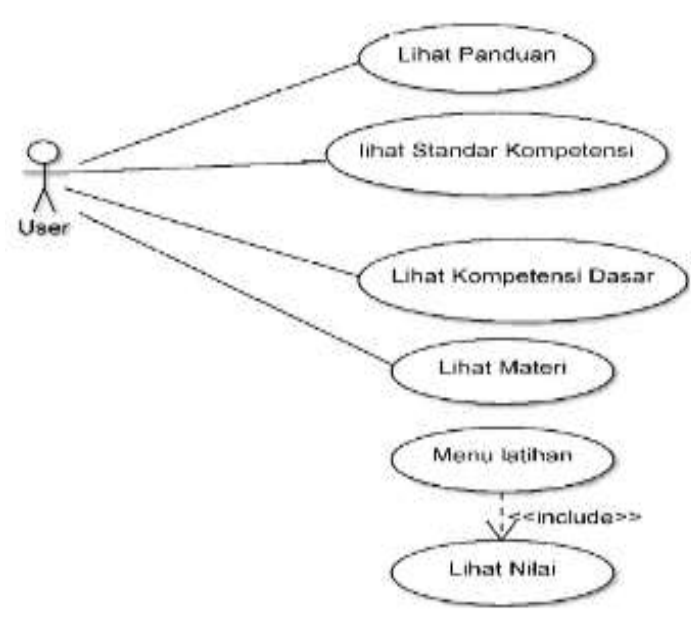

Gambar 1. Use Case Diagram Media Pembelajaran IPS

B. Activity diagram

Activity diagram menggambarkan aktivitas dari aplikasi yang dirancang. Adapun activity diagramnya pada Gambar 2 dan 3:

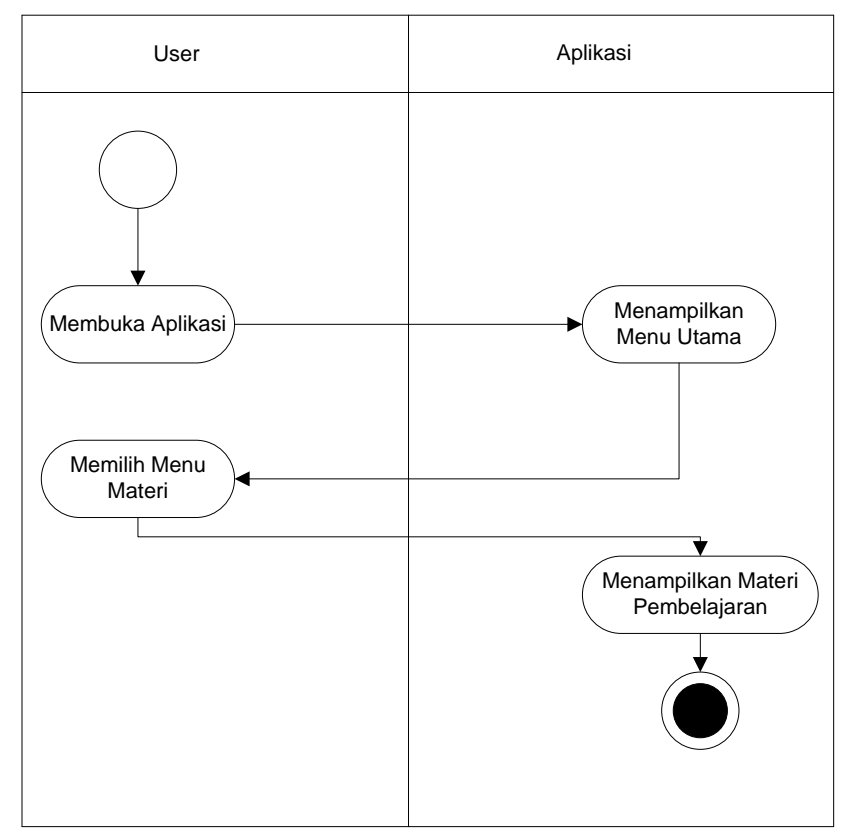

Gambar 2. Activity Diagram Menampilkan Materi 
E. Hutabri dan A. Dasa Putri, Perancangan Media Pembelajaran Interaktif Berbasis Android pada Mata Pelajaran Ilmu Pengetahuan Sosial untuk Anak Sekolah Dasar

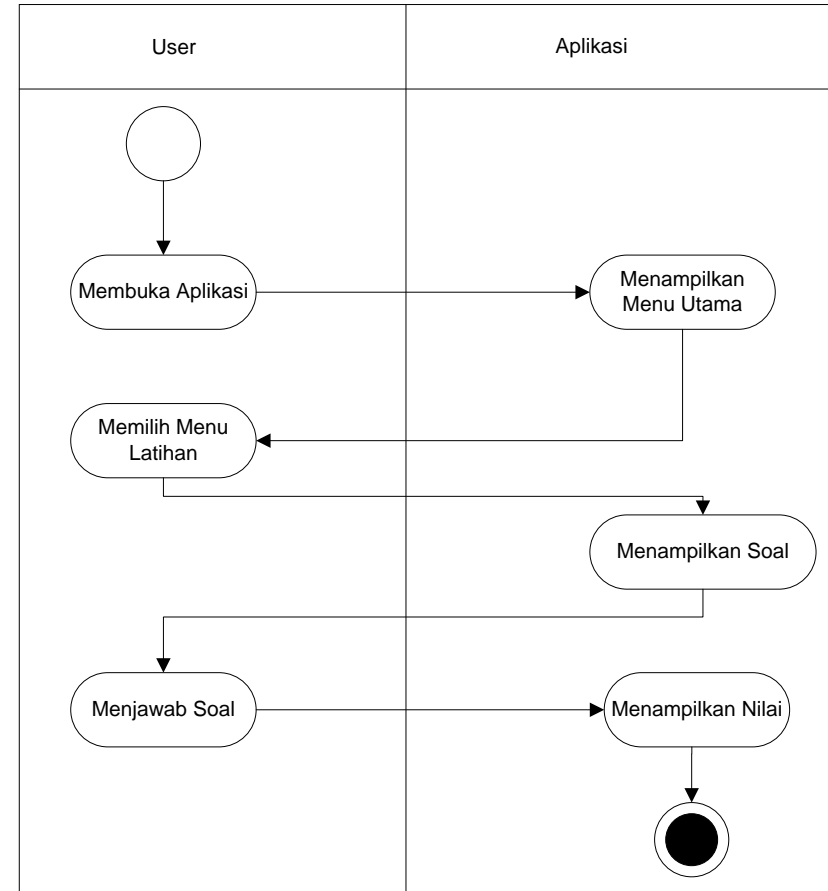

Gambar 3. Activity Diagram Latihan

\section{Sequence diagram}

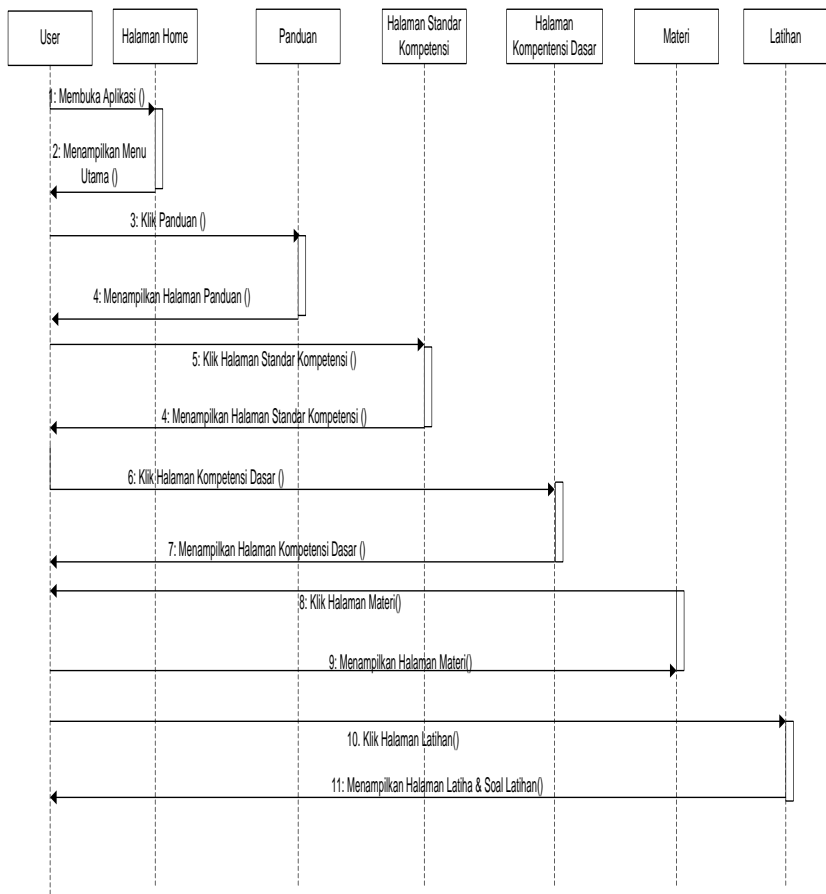

Gambar 4. Sequence Diagram Media Pembelajaran

Berdasarakan hasil rancangan yang telah dibuat menggunkan UML hasil implementasinya pada Gambar 5 :

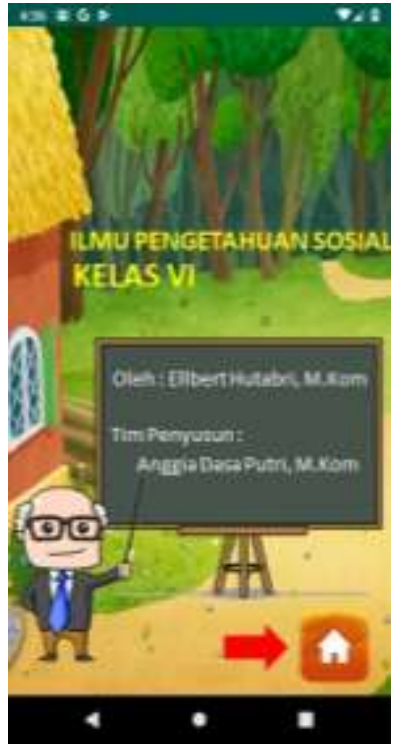

Gambar 5. Halaman Home

Halaman ini adalah halaman yang muncul ketika media pertama kali di jalankan. Berisi nama mata pelajaran, nama peneliti dan tim. Tombol berbentuk rumah berfungsi untuk masuk ke menu utama media pembelajaran.

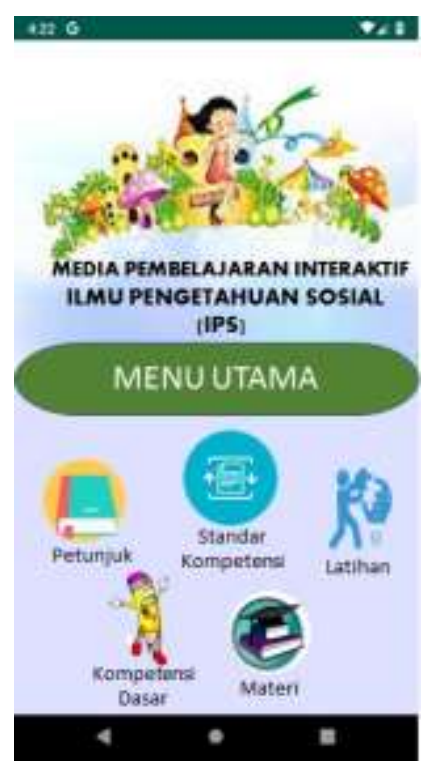

Gambar 6. Menu Utama

Menu utama berisi menu-menu yang terdiri dari petunjuk penggunaan, Standar kompetensi, Kompetensi dasar, Materi dan Latihan. 


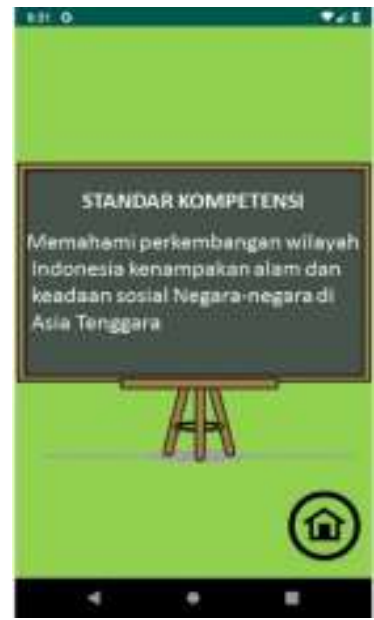

Gambar 7. Standar Kompetensi

Standar kompetensi bertujuan agar siswa mengetahui kualifikasi kemampuan yang menggambarkan penguasaan pengetahuan yang harus dimiliki oleh siswa.

Peta konsep merupakan suatu gambar yang memamaparkan suatu konsep yang menyatakan hubungan yang bermakna antara konsep-konsep dari suatu materi. Dapat dilihat pada Gambar 8.

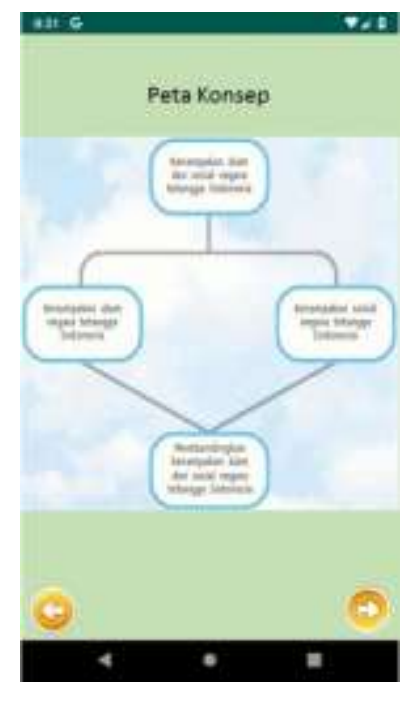

Gambar 8. Peta Konsep

Materi berisi pengenalan Negara-negara ASEAN sesuai dengan standar kompetensi yang akan dicapai. Materi dibuat dengan tampilan yang menarik agar minat belajar siswa meningkat.

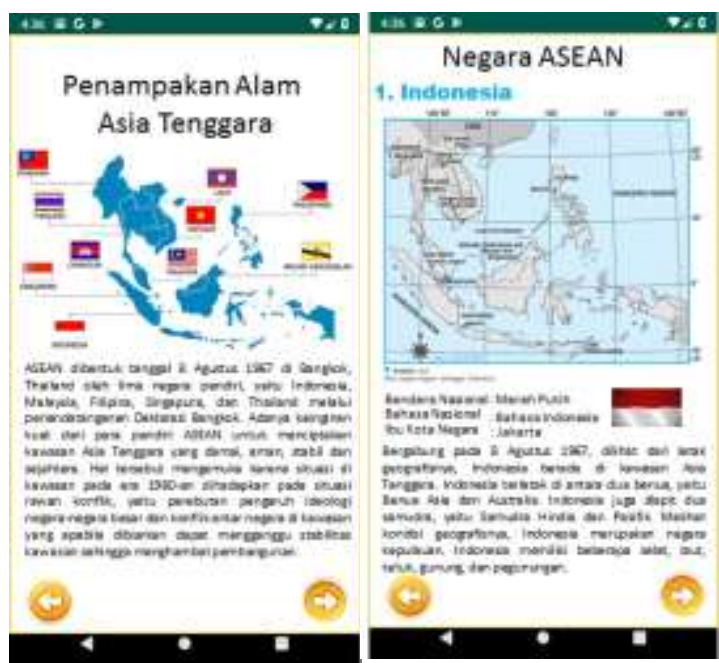

Gambar 9. Materi Pelajaran

\section{KESIMPULAN}

Berdasarkan hasil uji coba yang dilakukan dapat ditarik kesimpulan bahwa dengan adanya media pembelajaran interaktif siswa menjadi lebih bersemangat dalam belajar, media yang bisa di jalankan pada smatphone berbasis android siswa dapat belajar dirumah secara mandiri dengan bantuan orang tua. Diharapkan dengan menggunakan media interaktif berbasis android pada mata pelajaran IPS terjadi peningkatan pada nilai belajar siswa.

\section{REFERENSI}

[1] A. Purnomo, A. Muntholib, and S. Amin, "Model Pembelajaran Ilmu Pengetahuan Sosial (Ips) Pada Materi Kontroversi (Controversy Issues) Di Sekolah Menengah Pertama (Smp) Kota Semarang," J. Penelit. PendidikanA A, vol. 33, no. 1, pp. 13-26, 2016.

[2] F. Yasmi, E. Hutabri, and Asril, "Validasi Perkembangan Media Cd Interaktif Berbasis Karakter Pada Mata Kuliah Perkembangan Peserta Didik," in Prosiding Seminar Ilmiah Nasional Biologi Edukasi, 2008, p. 193.

[3] S. Muyaroah and M. Fajartia, "Pengembangan Media Pembelajaran Berbasis Android dengan menggunakan Aplikasi Adobe Flash CS 6 pada Mata Pelajaran Biologi," Innov. J. Curric. Educ. Technol., vol. 6, no. 2, pp. 22-26, 
E. Hutabri dan A. Dasa Putri, Perancangan Media Pembelajaran Interaktif Berbasis Android pada Mata Pelajaran Ilmu Pengetahuan Sosial untuk Anak Sekolah Dasar

2017.

[4] T. A. Dewi, "Implementasi Multimedia Interaktif Dalam Pembelajaran Ekonomi Di Sekolah," J. Pendidik. Ekon. UM Metro, vol. 3, no. 1, pp. 73-82, 2015.

[5] M. Istiqlal, "Pengembangan Multimedia Interaktif Dalam Pembelajaran Matematika," JIPMat, vol. 2, no. 1, 2017.

[6] E. Maiyana, "Pemanfaatan Android Dalam Perangan Aplikasi Kumpulan Doa," J. Sains dan Inform., vol. 1, pp. 5467, 2018.
[7] Rosa and Sallahudin, Rekayasa Perangkat Lunak. Bandung: Informatika, 2013.

[8] A. Noertjahyana, "Studi Analisis Rapid Aplication Development Sebagai Salah Satu Alternatif Metode Pengembangan Perangkat Lunak," J. Inform., vol. 3, no. 2, pp. 68-68, 2002. 